\title{
Short communication: Decrease of lipid profiles in cow milk by ultra-high-temperature treatment but not by pasteurization
}

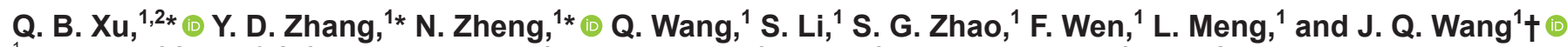 \\ ${ }^{1}$ Laboratory of Quality \& Safety Risk Assessment for Dairy Products of Ministry of Agriculture, Institute of Animal Sciences, \\ Chinese Academy of Agricultural Sciences, Beijing 100193, China \\ ${ }^{2}$ College of Animal Sciences and Technology, Huazhong Agricultural University, Wuhan 430070, China
}

\section{ABSTRACT}

Triglyceride (TG) and fatty acid profiles of raw $(\mathrm{RM})$, pasteurized $\left(\mathrm{PM}, 85^{\circ} \mathrm{C}\right.$ for $\left.15 \mathrm{~s}\right)$, and indirect UHT-treated (UM, $135^{\circ} \mathrm{C}$ for $15 \mathrm{~s}$ ) cow milk were investigated by a lipidomics approach. Ninety-four TG were identified and all were present at significantly lower concentrations in UM than in RM or PM, and free fatty acid contents were significantly higher in UM than in RM and PM, indicating that TG lipolysis occurred to a greater degree in UM than in RM and PM. In addition, UM contained significantly fewer unsaturated fatty acids (14 types) than those in RM and PM, including C14:1n-5, C15:1n-5, C16:1n-7, C17:1n-7, C18:1n9 cis, C18:2n-6 cis, C18:3n-3, C18:3n-6, C20:1, C20:2, C20: 3n-6, C20:3n-3, C20:4n-6, and C20:5n-3. However, we detected no significant differences between RM and PM in these fatty acids. In conclusion, UHT treatment, but not pasteurization, caused loss of the nutritional quality and bioactivity of cow milk lipid profiles.

Key words: cow milk, lipidomics, pasteurized treatment, UHT treatment

\section{Short Communication}

Lipids, the major energy source in cow milk, account for various physical, organoleptic, and manufacturing properties (Lopez et al., 2005). Dairy lipids also have anti-inflammatory properties against chronic diseases, such as cardiovascular diseases, cancer, and obesity (Lordan and Zabetakis, 2017), especially unsaturated fatty acids (FA) such as oleic acid (Benito et al., 2006), n-3 FA (Benito et al., 2006; Brick et al., 2016), and CLA (Ochoa, 2004). Thus, examination of the thermal properties of milk lipids is of particular importance with respect to nutritional and functional value, and

Received July 25, 2019.

Accepted October 11, 2019.

*These authors contributed equally to this work.

†Corresponding author: jiaqiwang@vip.163.com for technical applications in dairy industry (Lopez et al., 2006).

However, few studies have examined the effects of thermal treatment on milk lipids, particularly triglycerides (TG), which represent approximately $98 \%$ of the total lipid (fat) contents (Amara-Dali et al., 2007). A possible explanation for this lack of studies may be that available methods of analysis do not readily identify TG in milk. Milk lipid analysis is based on free FA (FFA) profiling, which fails to identify FFA in the form of TG (Sokol et al., 2015). In addition, pasteurization and UHT processing are common in the milk industry; however, information on their differences in lipid profiles is limited.

Recently, high-throughput lipidomics has become a rapidly expanding and active field, gaining increasing attention by researchers (Liu et al., 2018). Mass spectrometry-based lipidomics is a powerful strategy for quantification of individual molecular lipids and for determination of their FFA composition (Han and Gross, 2005; Shevchenko and Simons, 2010). Also, MUFA have been quantified in dairy products using MS-based ion monitoring mode (Hauff and Vetter, 2009), and 14 lipids were identified in goat, bovine, and soy milks using MS-based lipidomics (Li et al., 2017). Lipidomics based on $\mathrm{MS} / \mathrm{MS}^{\mathrm{ALL}}$, allowing spectra for all potential lipid species across the mass range, is a successful approach to characterize molecular lipid species in milk and its products (Sokol et al., 2015). However, most of the previous studies focused on limited lipid profiles. Thermal treatment has been reported to have a profound influence on milk lipid profiles, such as total lipid, CLA, FFA, and trans FA (Herzallah et al., 2005; Pereda et al., 2008; Sharma et al., 2016). Therefore, we can hypothesize that thermal treatment also affects milk lipidomics, including TG, FFA, and UFA. Milk lipidomics information is fragmented, complex, and largely lacking (Liu et al., 2018). Therefore, the purpose of this study was to prove this hypothesis by characterizing the lipid profiles of raw (RM), pasteurized (PM), and UHTtreated milk (UM) using an ultra-performance liquid 
chromatography (UPLC)-MS/MS ${ }^{\mathrm{ALL}}$-based lipidomics strategy.

Milk samples were obtained from a commercial dairy plant. The RM used for pasteurized and UHT treatments in each trial came from the same batch. Three batches of RM were used, all of which were treated similarly for pasteurization and UHT treatments. One pool from each sample (3 replicates) was analyzed. The $\mathrm{RM}$ was cooled to $<4^{\circ} \mathrm{C}$ and stored in an $\mathrm{RM}$ reception silo before commercial pasteurization $\left(85^{\circ} \mathrm{C}\right.$ for $15 \mathrm{~s}$, Shanghai Nanhua Transducer Manufacture Co. Ltd., Shanghai, China) or indirect UHT treatment $\left(135^{\circ} \mathrm{C}\right.$ for 15 s; FLEX-NG, Tetra Pak, Pully, Switzerland) within $24 \mathrm{~h}$ of milking. Then, samples were chilled to $-20^{\circ} \mathrm{C}$ until analysis.

The weight of the first batch of RM, which was collected from more than 1,500 dairy cows, was $40.6 \mathrm{t}$, of which $9.6 \mathrm{t}$ was pasteurized and $31 \mathrm{t}$ underwent UHT treatment. The second batch of RM was collected from more than 1,500 dairy cows and weighed $48.8 \mathrm{t}$, of which $8.3 \mathrm{t}$ was pasteurized and $40.5 \mathrm{t}$ was UHT-treated. The third batch of raw milk was collected from more than 1,200 dairy cows and weighed $34.6 \mathrm{t}$, of which $8.9 \mathrm{t}$ was pasteurized and $25.7 \mathrm{t}$ was UHT-treated.

Lipids were extracted using the methanol method as previously reported (Guan et al., 2017). Briefly, $10 \mu \mathrm{L}$ of milk was extracted and mixed with $490 \mu \mathrm{L}$ of methanol containing $2 \mathrm{nmol}$ of internal TG standard. After vortexing for $60 \mathrm{~s}$ and centrifuging at $10,000 \times g$ for 5 min, the supernatant was collected. Finally, $10 \mu \mathrm{L}$ of supernatant was diluted 1:10 in methanol, and $2 \mu \mathrm{L}$ of this mixture was loaded onto the liquid chromatograph for positive ion mass spectrometric analysis. Two microliters of each sample was loaded onto a UPLC system (Waters, Milford, MA) fitted with an auto sampler. An ethylene-bridged hybrid C18 reversed-phase column $(1.7 \mu \mathrm{m} ; 2.1 \mathrm{~mm} \times 100 \mathrm{~mm}$; Waters $)$ was maintained at $60^{\circ} \mathrm{C}$ and used to separate TG extracts. Phase A contained water:acetonitrile:formic acid (50:50:0.1, by vol), and phase B contained water:isopropanol:formic acid (10:90:0.1, by vol). Separation on UPLC was undertaken for $30 \mathrm{~min}$, with linear changes along with the gradient: 0 min $(75 \% \mathrm{~B}), 28 \mathrm{~min}(90 \% \mathrm{~B})$, and 28.1 to $30 \min (75 \% \mathrm{~B})$.

An API 4500 QTRAP mass spectrometer (Applied Biosystems/MDS Sciex, Framingham, MA) connected to the UPLC system was used for MS analysis (Guan et al., 2017). Briefly, assays were conducted in positive ionization mode and scan mode was set to obtain the TG quasimolecular ions as follows: declustering potential, $100 \mathrm{~V}$; mass range, 400-1,200 $\mathrm{m} / z$; scan rate, $1,000 \mathrm{Da} / \mathrm{s}$. To identify individual TG with specific FA chains, an instrument method based on multiple reac- tion monitoring was built with a scan rate of $10 \mathrm{kDa} / \mathrm{s}$ and range of 50 to $1,200 \mathrm{~m} / z$. The FFA content was determined using a MilkoScan apparatus (MilkoScan Type FT120, Foss Electric, Hillerød, Denmark), and FA content was determined using GC as described (Guan et al., 2017).

Data were analyzed using Student's t-test, and $P<$ 0.05 was considered significant. Multivariate analysis was conducted by a one-way ANOVA using Simca version 14.1 (Umetrics AB, Umea, Sweden), along with principal component analysis (PCA) and orthogonal partial least square-discriminant analysis (OPLS-DA).

The PCA revealed key differences between RM, PM, and UM samples $\left(\mathrm{R}^{2} \mathrm{X}=0.767, \mathrm{Q}^{2}=0.668\right.$, where $\mathrm{R}^{2}$ indicates goodness of fit, for either $\mathrm{X}$ or $\mathrm{Y}$ variations of the model, and $\mathrm{Q}^{2}$ signifies prediction goodness in model cross-validation), suggesting they were clearly separated (Figure 1A). The 2-dimensional score plots for the selected principal components $(\mathrm{PC} 1=99.6 \%$, $\left.\mathrm{PC} 2=0.3 \% ; \mathrm{R}^{2} \mathrm{X}=0.838, \mathrm{R}^{2} \mathrm{Y}=0.846, \mathrm{Q}^{2}=0.603\right)$ showed that UM was separated clearly from RM and PM; however, RM and PM seemed to belong to a same data set (Figure 1B). These results indicated that milk lipid profiles were changed by thermal treatment, and the effect of UHT treatment was more severe than that of pasteurization. Principal component analysis is a common method to evaluate the degree of separation of milk samples analyzed by lipidomics (Liu et al., 2018; Lu et al., 2018; Zhang et al., 2018). In addition, the OPLS-DA plots $\left(\mathrm{R}^{2} \mathrm{X}=0.838, \mathrm{R}^{2} \mathrm{Y}=0.846, \mathrm{Q}^{2}\right.$ $=0.603)$ revealed a distinct separation of $\mathrm{TG}$ profiles between RM, PM, and UM samples (Figure 1C). The OPLS-DA was used for data set analysis to produce models for investigating the differences in lipidomics data between different groups (Kirwan et al., 2012; Ravipati et al., 2015; Lu et al., 2018). Moreover, the receiver operating characteristics (ROC) curve is defined as the true- versus the false-positive classification rate, and represents the sensitivities and specificities of selected cut-off values (Greiner et al., 2000; Ravipati et al., 2015). The value for the area under the ROC curve for this model was 0.995 (Figure 1D), indicating that the model had excellent predictive power and clearly classified data of RM, PM, and UM samples.

Because of the uniqueness and functional specificity of lipids, lipidomics has become a vital metabolomics approach and has rapidly developed alongside developments in MS (Li et al., 2017; Liu et al., 2018). However, to date, only about 400 lipid species have been identified in cow milk, with several species remaining to be identified (Liu et al., 2018). In this study, 94 TG were identified in RM, PM, and UM samples by lipidomics using UPLC-MS/MS analysis (Figure 2). Here, C48:3 
TG with $818.5 \mathrm{~m} / z$ of MS/MS spectrum in 12.10 and $12.52 \mathrm{~min}$ in UPLC was taken as an example (Figure 2A). Triglycerides 16:1/16:1/16:1, 18:2/18:1/12:0, and 16:1/14:0/18:2 were identified at $12.10 \mathrm{~min}$ (Figure
2B), and TG 18:3/14:0/16:0 was identified in $818.5 \mathrm{~m} / \mathrm{z}$ at $12.52 \mathrm{~min}$ (Figure $2 \mathrm{C}$ ). The concentrations of all 94 TG were significantly lower in UM than in RM or PM $(P<0.05$; Figure 2D). Concentrations of TG were
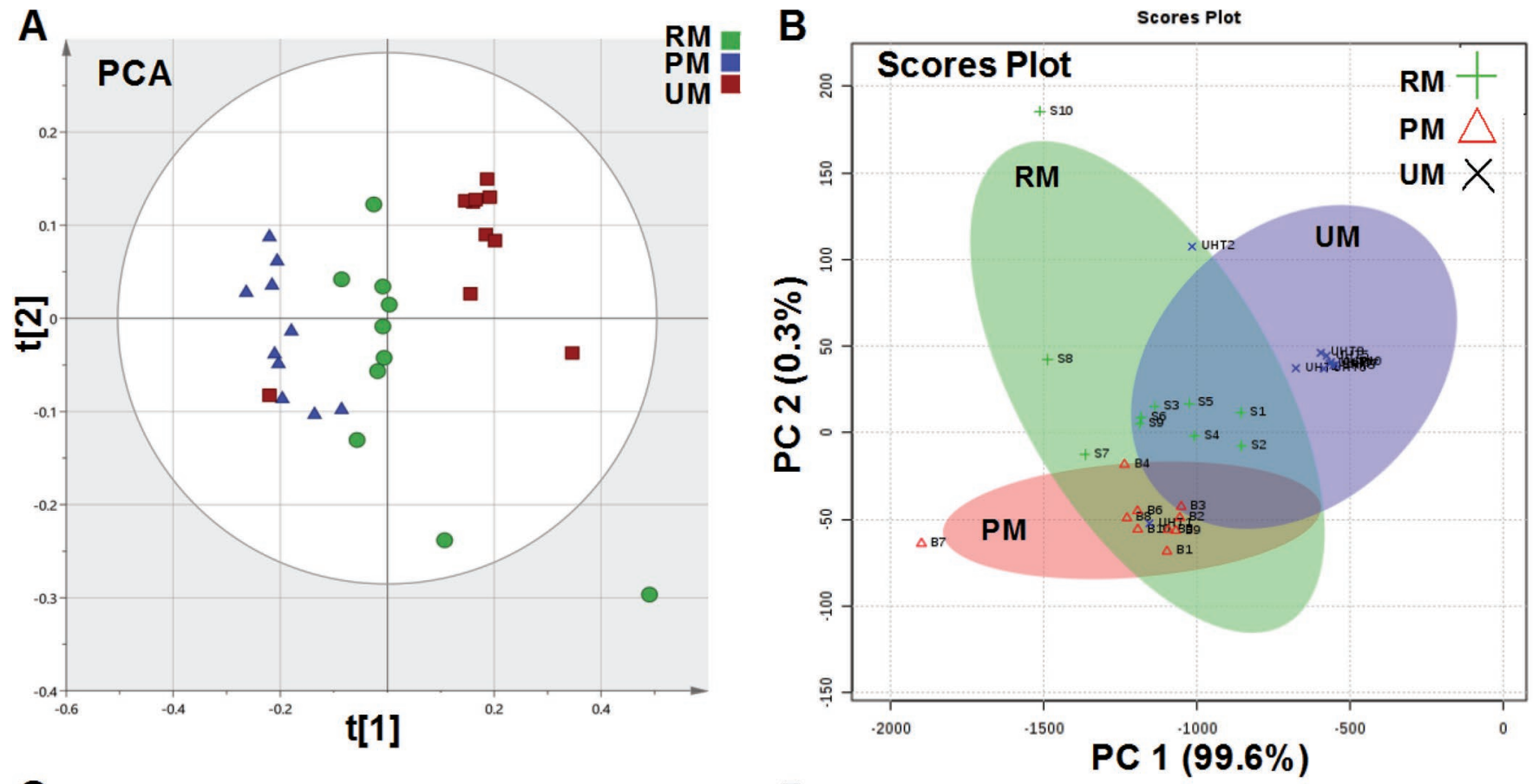

C
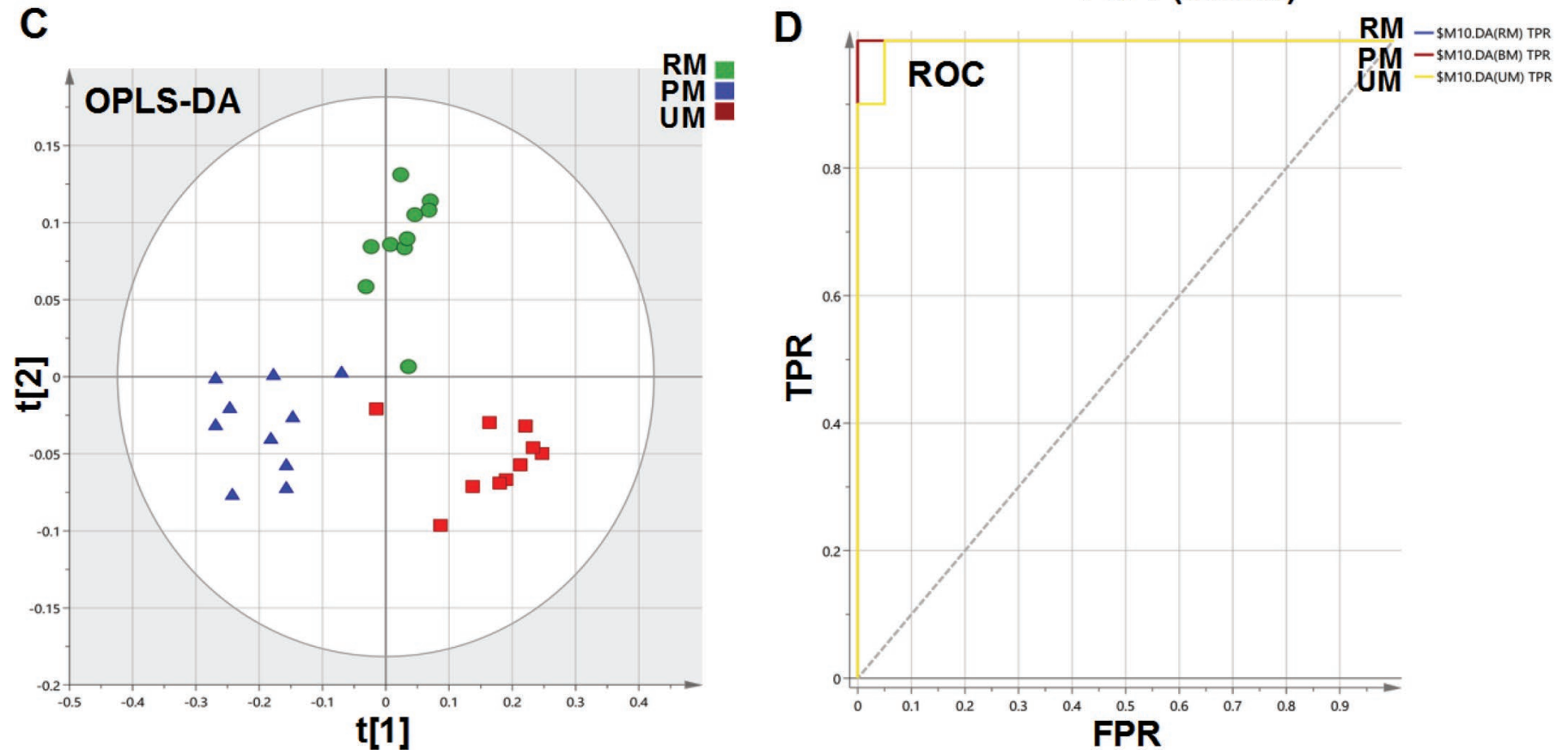

RM

PM

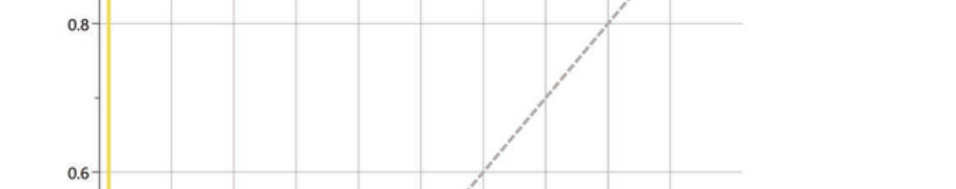

Figure 1. (A) Principal component analysis (PCA), (B) 2-dimensional score plot for selected principal components (PC); (C) orthogonal partial least squares discriminant analysis (OPLS-DA) score plots; and (D) receiver operating characteristics (ROC) plot for raw (RM, green circles), pasteurized (PM, blue triangles), and UHT-treated (UM, red squares) milk samples ( $\mathrm{n}=10)$. The ROC curve is defined as the truepositive classification rate (TPR) against the false-positive classification rate (FPR). t [1], t $[2]=$ test scores of principal components 1 and 2 in OPLS-DA analysis. Sample designations B1-10 = PM samples 1-10; S1-10 = samples 1-10; UHT1-10 = UM samples 1-10. 
decreased by about $41 \%$ on average by UHT treatment; however, no significant differences in TG concentrations were observed between RM and PM (Figure 2D). These data suggested that TG underwent lipolysis and that the degree of lipolysis was more intense in UM than in RM or PM. These results are consistent with a study in which TG were the main constituent removed during UHT treatment caused by lipolysis (Lu et al., 2018).

The extent of lipolysis in milk can be assessed by measuring FFA content (Pereda et al., 2008). Total FFA concentration in UM $(46 \pm 3.6 \mathrm{~m} M$; mean $\pm \mathrm{SD})$ was significantly higher than that in RM $(35.16 \pm 7.88$ $\mathrm{m} M ; P=0.012)$ and $\mathrm{PM}(40.45 \pm 4.05 ; P=0.031)$, being 1.31- and 1.14-fold higher that in RM and PM, respectively (Figure 3). However, there was no significant difference in FFA concentration between RM and PM. These data implied that thermal treatment can cause TG lipolysis, and that the lipolysis caused by UHT treatment was more profound than that in RM and PM. Lipolysis in milk can cause a rancid off-flavor, which is a challenge to the dairy industry (Deeth, 2006; Ray et al., 2013).

Normally, the lipolysis of TG to FFA does not occur because the milk fat globule membrane (MFGM) protects fat globules from hydrolysis by lipoprotein lipase (LPL; Deeth, 2006). The LPL is expressed by psychrotrophic bacteria, and accounts for most of the lipolytic activity in cow milk, and it is resistant to UHT treatment (Evers, 2004; Deeth, 2006; Ray et al., 2013). However, UHT treatment can cause denaturation and deposition of proteins on the MFGM (Dalgleish, 1990; Corredig and Dalgleish, 1996; Yang et al., 2018), which have a significant effect on interactions between whey proteins (mainly $\beta$-LG), fat globules, and MFGM (Corredig and Dalgleish, 1996; Lu et al., 2018). Interestingly, no significant effects were observed after pasteurization, perhaps because the pasteurization temperature was not high enough to disrupt the MFGM, which is limited at $<90^{\circ} \mathrm{C}$ (Corredig and Dalgleish, 1996). In addition, damage to the MFGM and fat globules caused by UHT treatment can lead to the exposure of "free" fat. Therefore, LPL resistant to UHT treatment can come into contact with free fat, hydrolyzing TG in the fat globule core to yield FFA (Evers, 2004). Moreover, not all undesirable lipolysis is caused by LPL; other heat-resistant extracellular lipases with characteristics different from those of LPL are present for lipolysis (Sørhaug and Stepaniak, 1997; Deeth, 2006). At higher temperatures, the MFGM would suffer greater disruption and the surface area of exposed lipid would be larger (Deeth, 2006). The lipolysis of TG provides indirect evidence of heat-resistant enzymes in UM. These results were consistent with previous studies in which the decrease of TG and increase of FFA in UM were also caused by lipolysis initiated by LPL (Deeth, 2006; Lu et al., 2018).

As the most common milk lipid, TG represents an energy source, and some components have specific bioactivity necessary for human health (Vinet and Zhedanov, 2011). Lipolysis of TG generates FFA, which contribute to flavor defects (rancidity, astringency, or bitterness) and alter the functionality of milk (Deeth, 2006; Ray et al., 2013). The FFA are more susceptible to oxidation than the TG (Aubourg, 2001), particularly FFA that comprise short or medium chains $(\mathrm{C} 4: 0-\mathrm{C} 12$ : 0 ). Our results were consistent with a study showing that the FFA content of milk was increased after thermal treatment due to the increased lipolysis and oxidation of TG (Pereda et al., 2008). Our results indicated that UHT treatment could adversely affect the taste and nutritional quality of milk. Milk lipids can possess bioactivity against chronic inflammation and enhanced activities against cancer and cardiovascular disease (Lordan and Zabetakis, 2017). Therefore, a decrease in milk lipids can induce a loss of milk functional value for human health. Although some LPL are resistant to pasteurization and UHT treatment, LPL does not cause profound lipolysis in PM (Deeth, 2006). The TG profile of PM was similar to that of RM, with similar nutritional benefits; thus, PM is an alternative to RM and poses a lesser risk of contamination by pathogens (Claeys et al., 2013, 2014).

As shown in Table 1, concentrations of UFA were significantly lower in UM than in RM and PM $(P<0.05)$; however, no significant difference was observed between RM and PM in UFA concentrations. The concentration of each UFA in RM and PM was significantly higher than that in UM $(P<0.05)$; however, we detected no significant difference between RM and PM in C14:1n-5, C15:1n-5, C16:1n-7 (palmitoleic acid), C17:1n-7, C18: 1n-9 cis (oleic acid), C18:2n-6 cis (linoleic acid), C18:3n -3 ( $\alpha$-linolenic acid), C18:3n-6 ( $\gamma$-linolenic acid), C20:1, C20:2, C20:3n-6, C20:3n-3, C20:4n-6 (arachidonic acid), and C20:5n-3. The concentration of UFA was decreased by $53 \%$, on average, in UM compared with RM.

Unsaturated FA in milk have various bioactivities. For example, oleic acid has antihypertensive activity and exerts cardiovascular benefits, and linolenic and linoleic acids are essential for human health (Terés et al., 2008). Fatty acids C18:3n-3, C20:3n-3, and C20:5n -3 belong to the n-3 (omega-3) FA family, which may protect against asthma and have anti-inflammatory activity; however, it can be inactivated by UHT treatment and boiling (Pereda et al., 2008; Brick et al., 2016). Moreover, supplementation of milk with oleic acid and n-3 FA can reduce serum low-density lipo- 
A

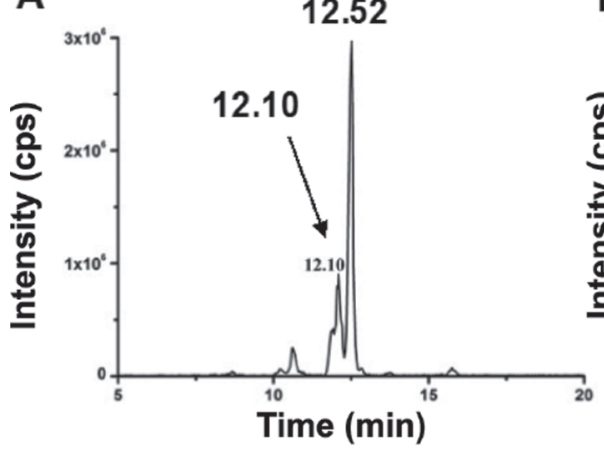

D

16:0/4:0/16:0 TG
18:1/16:0/18:1 TG 16:0/6:0/16:0 TG 18:1/4:0/16:0 TG 16:0/18:1/16:0 TG 16:0/18:1/14:0 TG

18:1/14:0/16:0 TG

18:1/4:0/18:1 TG 16:0/10:0/16:0 TG 18:1/14:0/18:1 TG 16:0/10:0/14:0 TG

18:1/12:0/16:0 TG 16:0/12:0/16:0 TG 18:1/18:1/18:1 TG 16:0/14:0/16:0 TG 4:0/14:0/16:0 TG 18:1/16:0/18:0 TG 18:1/12:0/18:1 TC 18:1/14:0/14:0 TG 18:1/4:0/18:0 TG 18:1/10:0/18:1 TG

政

18:1/16:0/6:0 TG

16:0/18:0/4:0 TG

18:1/18:0/18:1 TG

18:1/8:0/16:0 TG

18:1/14:0/4:0 TG

18:1/16:0/10:0 TG

12:0/14:0/18:0 TG

16:0/18:2/16:0 TG

16:0/12:0/18:0 TG

16:0/12:0/14:0 TG

14:0/16:0/14:0 TG

14:0/14:0/4:0 TG

18:2/16:0/18:1 TG

16:0/10:0/18:0 TG

14:0/12:0/14:0 TG

18:1/12:0/4:0 TG

16:0/16:0/16:0 TG

14:0/10:0/18:0 TG

18:1/14:1/16:0 TG

12:0/12:0/8:0 TG

18:1/6:0/14:0 TG

4:0/12:0/16:0 TG

18:1/15:0/16:0 TG

18:1/12:0/14:0 TG

16:0/14:0/18:0 TG

12:0/10:0/12:0 TG-

\section{0 Concentration $(\mu M)$}

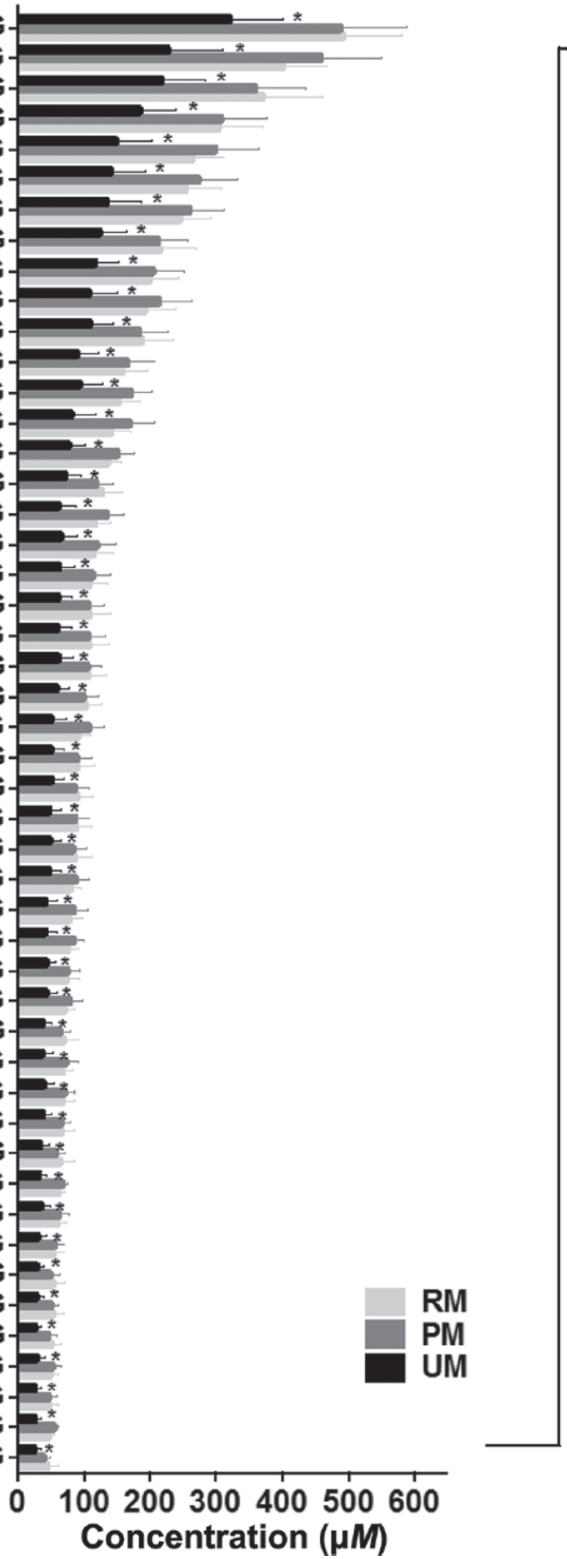

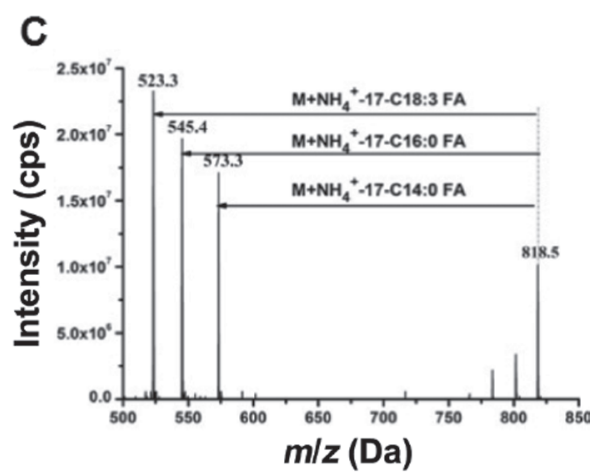

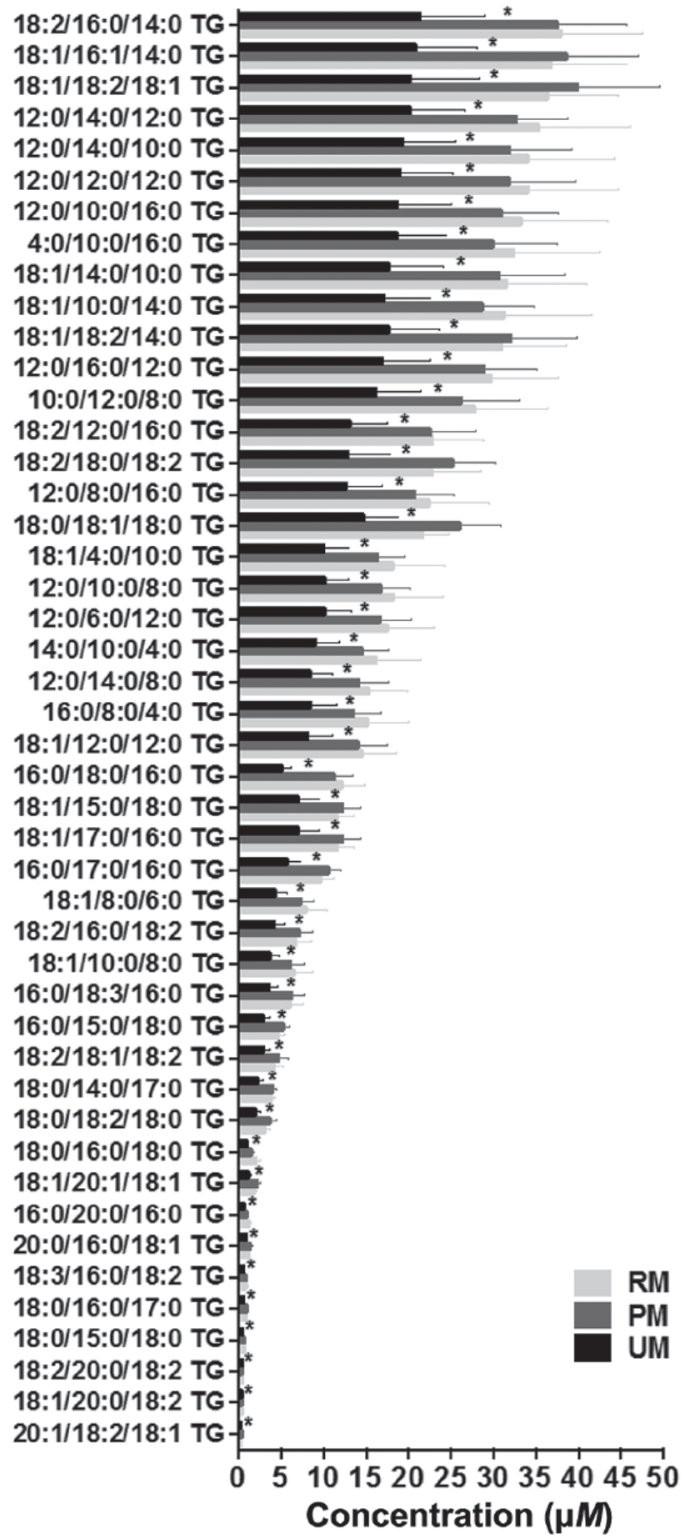

Figure 2. Ultra-performance liquid chromatography tandem mass spectrometry (UPLC-MS) analysis (A, B, and C) of concentrations (D) of triglycerides (TG) in cow milk. (A) An example showing UPLC of C48:3 TG; (B) MS/MS spectrum of 818.5 mass:charge ratio $(\mathrm{m} / z)$ at 12.10 min, which corresponds to TG 16:1/16:1/16:1, 18:2/18:1/12:0, and 16:1/14:0/18:2; (C) MS/MS spectrum of $818.5 \mathrm{~m} / z$ at $12.52 \mathrm{~min}$, which corresponds to 18:3/14:0/16:0 TG; (D) concentrations of 94 TG in raw (RM), pasteurized (PM), and UHT-treated (UM) milk samples. Bars represent the mean $\pm \mathrm{SD}(\mathrm{n}=10)$. ${ }^{*} P<0.05$, significantly different compared with RM and PM. FA = fatty acid; cps $=$ counts per second. 
Table 1. Concentrations of UFA in raw (RM), pasteurized (PM), and UHT-treated (UM) cow milk samples $(\mathrm{n}=3)$

\begin{tabular}{|c|c|c|c|c|c|}
\hline \multirow{2}{*}{$\begin{array}{l}\text { Item } \\
(\mathrm{mg} / 100 \mathrm{~g} \text { of lipid })\end{array}$} & \multicolumn{3}{|c|}{ Treatment } & \multirow[b]{2}{*}{ SD } & \multirow[b]{2}{*}{$P$-value } \\
\hline & $\mathrm{RM}$ & $\mathrm{PM}$ & UM & & \\
\hline UFA & $1,282.67^{\mathrm{a}}$ & $1,241.99^{\mathrm{a}}$ & $605.66^{\mathrm{b}}$ & 197.84 & 0.02 \\
\hline C14:1n-5 & $17.43^{\mathrm{a}}$ & $17.0^{\mathrm{a}}$ & $11.27^{\mathrm{b}}$ & 1.86 & 0.31 \\
\hline C15:1n-5 & $608.12^{\mathrm{a}}$ & $588.63^{\mathrm{a}}$ & $329.73^{\mathrm{b}}$ & 96.09 & 0.04 \\
\hline C16:1n-7 & $36.72^{\mathrm{a}}$ & $35.37^{\mathrm{a}}$ & $19.90^{\mathrm{b}}$ & 5.83 & 0.04 \\
\hline C17:1n-7 & $4.19^{\mathrm{a}}$ & $4.01^{\mathrm{a}}$ & $2.38^{\mathrm{b}}$ & 0.61 & 0.03 \\
\hline C18:1n-9 cis & $546.51^{\mathrm{a}}$ & $530.79^{\mathrm{a}}$ & $221.36^{\mathrm{b}}$ & 82.74 & 0.01 \\
\hline $\mathrm{C} 18: 2 \mathrm{n}-6 \mathrm{cis}$ & $48.64^{\mathrm{a}}$ & $45.43^{\mathrm{a}}$ & $9.99^{\mathrm{b}}$ & 6.19 & $<0.01$ \\
\hline C18:3n-3 & $5.41^{\mathrm{ab}}$ & $5.88^{\mathrm{a}}$ & $4.95^{\mathrm{b}}$ & 1.05 & 0.64 \\
\hline C18:3n-6 & $0.86^{\mathrm{a}}$ & $0.98^{\mathrm{a}}$ & $0.23^{\mathrm{b}}$ & 0.23 & 0.03 \\
\hline C20:1 & $1.88^{\mathrm{a}}$ & $2.15^{\mathrm{a}}$ & $0.26^{\mathrm{b}}$ & 0.62 & 0.04 \\
\hline C20:2 & $0.85^{\mathrm{a}}$ & $1.05^{\mathrm{a}}$ & $0.28^{\mathrm{b}}$ & 0.13 & $<0.01$ \\
\hline C20:3n-3 & 0.37 & 0.41 & 0.28 & 0.38 & 0.33 \\
\hline C20:3n-6 & $3.0^{\mathrm{a}}$ & $2.8^{\mathrm{a}}$ & $0.73^{\mathrm{b}}$ & 0.08 & $<0.01$ \\
\hline C20:4n-6 & $4.2^{\mathrm{a}}$ & $3.94^{\mathrm{a}}$ & $0.75^{\mathrm{b}}$ & 0.51 & $<0.01$ \\
\hline C20:5n-3 & $4.5^{\mathrm{a}}$ & $3.54^{\mathrm{ab}}$ & $3.55^{\mathrm{b}}$ & 0.52 & 0.18 \\
\hline
\end{tabular}

${ }^{\mathrm{a}, \mathrm{b}}$ Means within a row with different superscripts differ $(P<0.05)$.

proteins, glucose, and homocysteine of individuals with metabolic syndrome (Benito et al., 2006). Thus, the decrease in beneficial UFA in UM may lead to the loss of these valuable properties.

There are several possible reasons for the observed reduction of FA in UM. First, thermal treatment may cause physical and chemical changes (e.g., oxidation and formation of trans FA isomers; Semma, 2002; Herzallah et al., 2005). The UHT treatment can induce oxidation of UFA bound to casein, thereby producing off-flavor aldehydes (Ramshaw and Dunstone, 1969). It can also induce saturation of unsaturated bonds, result-

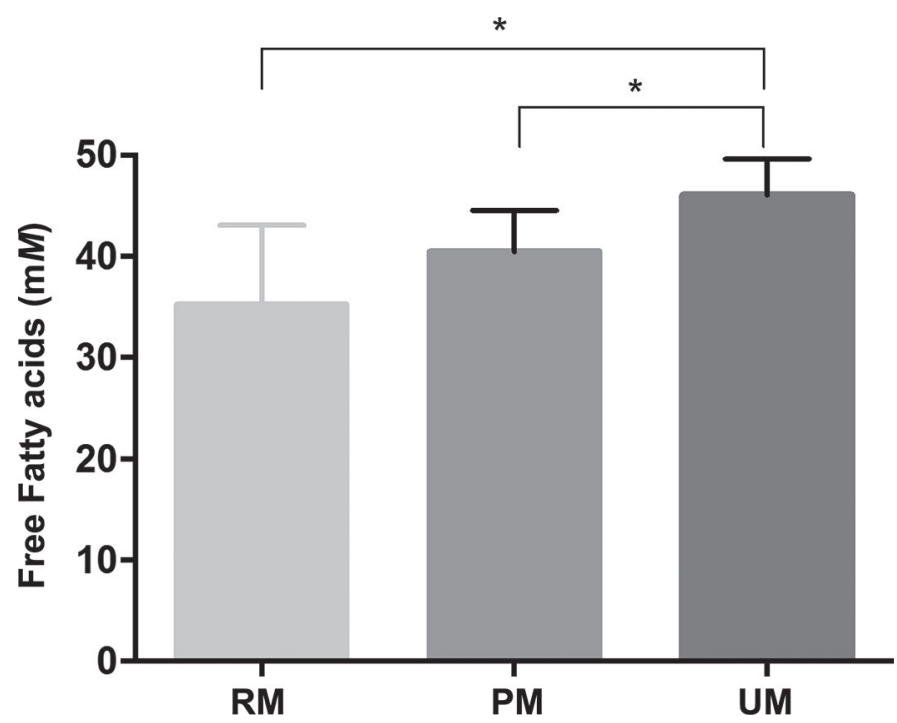

Figure 3. Concentrations of free fatty acids of raw (RM), pasteurized (PM), and UHT-treated (UM) milk. The bars represent the mean $\pm \mathrm{SD}(\mathrm{n}=10) .{ }^{*} P<0.05 ;{ }^{* *} P<0.01$. ing in the production of ketones by $\beta$-oxidation (Pereda et al., 2008). Second, some volatile FA could be lost during UHT treatment. Another reason for FA decrease is the activity of heat-resistant enzymes. For instance, enzymes that metabolize n-3 FA can be released by mechanical damage to microvesicles; therefore, UHT treatment can lead to a drastic reduction in n-3 FA content in milk (Brick et al., 2016). Also, cheese CLA was decreased by 21 and $53 \%$ after heating in a microwave oven for 5 and $10 \mathrm{~min}$, respectively (Herzallah et al., 2005).

In conclusion, UHT treatment, but not pasteurization, can reduce the nutritional quality and function (or bioactivity) of milk lipids, leading to a loss of positive effects on human health. Therefore, PM represents a safer and healthier alternative for consumers who usually drink RM and UM, respectively (Claeys et al., 2013, 2014). Moreover, the TG and FA identified herein could also be thermal biomarkers that can distinguish UM from PM in the market. To our knowledge, this is the first study to examine the effects of thermal treatment on TG and FA profiles of cow milk using lipidomics. These data increase our understanding of differences in lipid composition of milk following different thermal treatments. Ultimately, these results can help to improve the quality of dairy products.

\section{ACKNOWLEDGMENTS}

The authors thank Modern Farming (Group) Co. Ltd. (Maanshan, China) for providing processing equipment and raw milk samples. We also thank the Institute of Chemistry, Chinese Academy of Sciences, for assistance with triglyceride analyses. The research was supported 
by the National Natural Science Foundation of China (31601962), Special Fund for Agro-scientific Research in the Public Interest (201403071), the Introduction of International Advanced Agricultural Science and Technology Program (2015-Z12), the Modern Agro-Industry Technology Research System of China (CARS-36), and the Agricultural Science and Technology Innovation Program (ASTIP-IAS12; Beijing, China).

\section{REFERENCES}

Amara-Dali, W. B., P. Lesieur, F. Artzner, N. Karray, H. Attia, and M. Ollivon. 2007. Anhydrous goat's milk fat: Thermal and structural behaviors studied by coupled differential scanning calorimetry and X-ray diffraction. 2. Influence of cooling rate. J. Agric. Food Chem. 55:4741-4751. https://doi.org/10.1021/jf063210p.

Aubourg, S. P. 2001. Fluorescence study of the pro-oxidant effect of free fatty acids on marine lipids. J. Sci. Food Agric. 81:385390. https://doi.org/10.1002/1097-0010(200103)81:4<385::AIDJSFA821>3.0.CO;2-X.

Benito, P., J. Caballero, J. Moreno, C. Gutiérrez-Alcántara, C. Muñoz, G. Rojo, S. Garcia, and F. C. Soriguer. 2006. Effects of milk enriched with $\omega-3$ fatty acid, oleic acid and folic acid in patients with metabolic syndrome. Clin. Nutr. 25:581-587. https://doi.org/ 10.1016/j.clnu.2005.12.006.

Brick, T., Y. Schober, C. Böcking, J. Pekkanen, J. Genuneit, G. Loss, J.-C. Dalphin, J. Riedler, R. Lauener, W. A. Nockher, H. Renz, O. Vaarala, C. Braun-Fahrländer, E. von Mutius, M. J. Ege, P. I. Pfefferle, A. Karvonen, P. Tiittanen, M.-L. Dalphin, B. Schaub, M. Depner, S. Illi, and M. Kabesch. 2016. $\omega$-3 fatty acids contribute to the asthma-protective effect of unprocessed cow's milk. J. Allergy Clin. Immunol. 137:1699-1706.e13. https://doi.org/10.1016/j.jaci 2015.10.042

Claeys, W. L., S. Cardoen, G. Daube, J. De Block, K. Dewettinck, K. Dierick, L. De Zutter, A. Huyghebaert, H. Imberechts, P. Thiange, Y. Vandenplas, and L. Herman. 2013. Raw or heated cow milk consumption: Review of risks and benefits. Food Control 31:251262. https://doi.org/10.1016/j.foodcont.2012.09.035.

Claeys, W. L., C. Verraes, S. Cardoen, J. De Block, A. Huyghebaert, K. Raes, K. Dewettinck, and L. Herman. 2014. Consumption of raw or heated milk from different species: An evaluation of the nutritional and potential health benefits. Food Control 42:188-201. https://doi.org/10.1016/j.foodcont.2014.01.045.

Corredig, M., and D. G. Dalgleish. 1996. Effect of different heat treatments on the strong binding interactions between whey proteins and milk fat globules in whole milk. J. Dairy Res. 63:441-449. https://doi.org/10.1017/S0022029900031940.

Dalgleish, D. G. 1990. Denaturation and aggregation of serum proteins and caseins in heated milk. J. Agric. Food Chem. 38:1995-1999. https://doi.org/10.1021/jf00101a001.

Deeth, H. C. 2006. Lipoprotein lipase and lipolysis in milk. Int. Dairy J. 16:555-562. https://doi.org/10.1016/j.idairyj.2005.08.011.

Evers, J. M. 2004. The milkfat globule membrane-Methodologies for measuring milkfat globule (membrane) damage. Int. Dairy J. 14:747-760. https://doi.org/10.1016/j.idairyj.2004.01.006.

Greiner, M., D. Pfeiffer, and R. Smith. 2000. Principles and practical application of the receiver-operating characteristic analysis for diagnostic tests. Prev. Vet. Med. 45:23-41. https://doi.org/10.1016/ S0167-5877(00)00115-X.

Guan, M., D. Dai, L. Li, J. Wei, H. Yang, S. Li, Y. Zhang, Y. Lin, S. Xiong, and Z. Zhao. 2017. Comprehensive qualification and quantification of triacylglycerols with specific fatty acid chain composition in horse adipose tissue, human plasma and liver tissue. Talanta 172:206-214. https://doi.org/10.1016/j.talanta.2017.05.042.

Han, X., and R. W. Gross. 2005. Shotgun lipidomics: Electrospray ionization mass spectrometric analysis and quantitation of cellular lipidomes directly from crude extracts of biological samples. Mass Spectrom. Rev. 24:367-412. https://doi.org/10.1002/mas.20023.

Hauff, S., and W. Vetter. 2009. Quantitation of cis- and trans-monounsaturated fatty acids in dairy products and cod liver oil by mass spectrometry in the selected ion monitoring mode. J. Agric. Food Chem. 57:3423-3430. https://doi.org/10.1021/jf803665u.

Herzallah, S. M., M. A. Humeid, and K. M. Al-Ismail. 2005. Effect of heating and processing methods of milk and dairy products on conjugated linoleic acid and trans fatty acid isomer content. J. Dairy Sci. 88:1301-1310. https://doi.org/10.3168/jds.S0022 -0302(05)72796-X.

Kirwan, G. M., E. Johansson, R. Kleemann, E. R. Verheij, A. M. Wheelock, S. Goto, J. Trygg, and C. E. Wheelock. 2012. Building multivariate systems biology models. Anal. Chem. 84:7064-7071. https://doi.org/10.1021/ac301269r.

Li, Q., Y. Zhao, D. Zhu, X. Pang, Y. Liu, R. Frew, and G. Chen. 2017. Lipidomics profiling of goat milk, soymilk and bovine milk by UPLC-Q-Exactive Orbitrap mass spectrometry. Food Chem. 224:302-309. https://doi.org/10.1016/j.foodchem.2016.12.083.

Liu, Z., S. Rochfort, and B. Cocks. 2018. Milk lipidomics: What we know and what we don't. Prog. Lipid Res. 71:70-85. https://doi .org/10.1016/j.plipres.2018.06.002.

Lopez, C., V. Briard-Bion, B. Camier, and J.-Y. Gassi. 2006. Milk fat thermal properties and solid fat content in Emmental cheese: A differential scanning calorimetry study. J. Dairy Sci. 89:2894-2910. https://doi.org/10.3168/jds.S0022-0302(06)72562-0.

Lopez, C., P. Lesieur, C. Bourgaux, and M. Ollivon. 2005. Thermal and structural behavior of anhydrous milk fat. 3. Influence of cooling rate. J. Dairy Sci. 88:511-526. https://doi.org/10.3168/jds .S0022-0302(05)72713-2.

Lordan, R., and I. Zabetakis. 2017. Invited review: The anti-inflammatory properties of dairy lipids. J. Dairy Sci. 100:4197-4212. https: //doi.org/10.3168/jds.2016-12224.

Lu, J., J. Pickova, J. L. Vázquez-Gutiérrez, and M. Langton. 2018. Influence of seasonal variation and ultra high temperature processing on lipid profile and fat globule structure of Swedish cow milk. Food Chem. 239:848-857. https://doi.org/10.1016/j.foodchem 2017.07.018.

Ochoa, J. J. 2004. Conjugated linoleic acids (CLAs) decrease prostate cancer cell proliferation: Different molecular mechanisms for cis-9,trans-11 and trans-10,cis-12 isomers. Carcinogenesis 25:11851191. https://doi.org/10.1093/carcin/bgh116.

Pereda, J., V. Ferragut, J. M. Quevedo, B. Guamis, and A. J. Trujillo. 2008. Effects of ultra-high-pressure homogenization treatment on the lipolysis and lipid oxidation of milk during refrigerated storage. J. Agric. Food Chem. 56:7125-7130. https://doi.org/10.1021/ jf800972m.

Ramshaw, E. H., and E. A. Dunstone. 1969. Volatile compounds associated with the off-flavour in stored casein. J. Dairy Res. 36:215223. https://doi.org/10.1017/S0022029900012711.

Ravipati, S., D. R. Baldwin, H. L. Barr, A. W. Fogarty, and D. A. Barrett. 2015. Plasma lipid biomarker signatures in squamous carcinoma and adenocarcinoma lung cancer patients. Metabolomics 11:1600-1611. https://doi.org/10.1007/s11306-015-0811-x.

Ray, P. R., K. Chatterjee, C. Chakraborty, and P. K. Ghatak. 2013. Lipolysis of milk: A review. Int. J. Agric. Sci. Vet. Med. 1:58-74.

Semma, M. 2002. Trans fatty acids: Properties, benefits and risks. J. Health Sci. 48:7-13. https://doi.org/10.1248/jhs.48.7.

Sharma, P., I. Oey, and D. W. Everett. 2016. Thermal properties of milk fat, xanthine oxidase, caseins and whey proteins in pulsed electric field-treated bovine whole milk. Food Chem. 207:34-42. https://doi.org/10.1016/j.foodchem.2016.03.076.

Shevchenko, A., and K. Simons. 2010. Lipidomics: Coming to grips with lipid diversity. Nat. Rev. Mol. Cell Biol. 11:593-598. https:// doi.org/10.1038/nrm2934.

Sokol, E., T. Ulven, N. J. Faergeman, and C. S. Ejsing. 2015. Comprehensive and quantitative profiling of lipid species in human milk, cow milk and a phospholipid-enriched milk formula by GC and MS/MS ${ }^{\text {ALL }}$. Eur. J. Lipid Sci. Technol. 117:751-759. https://doi .org/10.1002/ejlt.201400575. 
Sørhaug, T., and L. Stepaniak. 1997. Psychrotrophs and their enzymes in milk and dairy products: Quality aspects. Trends Food Sci. Technol. 8:35-41. https://doi.org/10.1016/S0924-2244(97)01006-6.

Terés, S., G. Barcelo-Coblijn, M. Benet, R. Alvarez, R. Bressani, J. E. Halver, and P. V. Escriba. 2008. Oleic acid content is responsible for the reduction in blood pressure induced by olive oil. Proc. Natl. Acad. Sci. USA 105:13811-13816. https://doi.org/10.1073/ pnas.0807500105.

Vinet, L., and A. Zhedanov. 2011. A 'missing' family of classical orthogonal polynomials. J. Phys. A Math. Theor. 44:085201. https:/ /doi.org/10.1088/1751-8113/44/8/085201.

Yang, Y., N. Zheng, X. Zhao, J. Yang, Y. Zhang, R. Han, Y. Qi, S. Zhao, S. Li, F. Wen, T. Guo, C. Zang, and J. Wang. 2018. Changes in bovine milk fat globule membrane proteins caused by heat procedures using a label-free proteomic approach. Food Res. Int. 113:1-8. https://doi.org/10.1016/j.foodres.2018.06.046.
Zhang, Y. D., P. Li, N. Zheng, Z. W. Jia, N. Meruva, A. Ladak, G. Cleland, F. Wen, S. L. Li, S. G. Zhao, and J. Q. Wang. 2018 A metabolomics approach to characterize raw, pasteurized, and ultra-high temperature milk using ultra-performance liquid chromatography-quadrupole time-of-flight mass spectrometry and multivariate data analysis. J. Dairy Sci. 101:9630-9636. https:// doi.org/10.3168/jds.2018-14441.

\section{ORCIDS}

Q. B. Xu ๑ https://orcid.org/0000-0001-8461-9924

N. Zheng (ㄴ) https://orcid.org/0000-0002-5365-9680

J. Q. Wang @ https://orcid.org/0000-0001-8841-0124 